Honey Production in the British Isles

By R. O. B. Manley. Pp $328+15$ plates. (London : Faber and Faber, Lt $\$$ M 1946.) 18s. net.

W ${ }^{H E N}$ a mplorn technical work sells second-hand for equadorably more than its published price, there jea dear case for re-issue. The above is substantia "ly" a re-issue of the former edition, with errata corrected and some new illustrations.

It is the only book on bee-keeping in Great Britain written by one who depends upon honey production for his livelihood. If more amateur bee-keepers followed the professionals in choice of apparatus and methods of management, more of them could develop their hobby into a profitable side-line or even a means of livelihood.

Everything written by Mr. Manley makes good reading and is worthy of careful study. It is only on re-reading this work, now ten years old, that one realizes how far the first edition was in advance of the teaching of that time. Many bee-keepers have yet much leeway to make up. Some of them know it and will welcome this re-issue.

One could wish that the author could have found time to re-write some few parts of the work, for he surely has something to teach us on hive ventilation; treatment of disease also would be brought up to date.

Mr. Manley is perhaps the only writer who gives really reliable and detailed information on the costs and profits of commercial bee-keeping. This information is all on a pre-war basis, but as figures were then at least stable the reader can make his own corrections, whereas comparison at a later date with 1946 figures would be by no means simple.

$$
2 / 2
$$

E. B. WEDMORE

\section{History of Air Navigation}

By Arthur J. Hughes.nPp. 154. (London: George Allen and Uny (Whe, 1946.) 10s. 6d. net.

A LTHOUCH pullished in 1946, it appears from the reface that this book was completed in 1944. We was not possible, therefore, to give any inforr nayigation, of which particulars at that time had not been released. The book was thus out of date before it was published. It is disappointing in other ways ; illustrations of a great variety of instruments are given, but in many cases without sufficient description for those who are not familiar with them to understand how they are used. The reader will look in vain for any account of special methods of navigation adopted for polar flights. The chapter on ancient navigation has nothing to do with air navigation. Although aviation has a short history, developments - stimulated as they have been by two great wars-have been rapid. A fascinating story of the history of air navigation might have been written. This book seems to fall between two stools: it is not sufficiently technical and specialized for the expert, but it is too technical and assumes too much basic knowlpdge for the general reader.

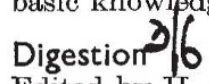

Edited by H. J. Vonk ter. Mansour-Bek and E. J. Slijper. Part f (roulæ Biologicæ, Vol. 21.) Pp. xvi+284 A A A isterdam: Dr. W. Junk, 1946.)

TE glitors explain in the preface that the 1 Ianuscripts of this volume were ready in 1939 , but the difficulties caused by the War and the German occupation of the Netherlands delayed printing until this year. The whole volume is now to be published in three parts, the first two dealing with vertebrates and the third with invertebrates, of which this is the first. An appendix, containing the accumulated data of the last seven years, is planned and will be included in the third part.

The present part contains articles on the physiological anatomy of the digestive organs and on the food of vertebrates, on the rhythmic action of the glands of secretion and their composition, and on the digestive enzymes. With one exception (an article by Linderström-Lang and Holter on the distribution of enzymes in the mucous membrane of the gastrointestinal canal) the authors are all Dutch. We may notice particularly the article on the digestive enzymes by Chr. Engel, which is a valuable summary of the knowledge up to 1939. However, in view of the great progress made in recent years on the pancreatic enzymes, there is no doubt that much of the older work on the peptidases, etc., of the intestinal canal will need re-evaluation. J. A. V. BUTLER

Experimental Plastics and Synthetic Resins 3/2 By Dr. G. F. D'Aleli i Rp. ix +185 . (New York : John Wiley apd Sons, Inc.; London : Chapman and Hall, Ltd., 194203 dollars.

THzs fyubucation should prove of considerable value t\$ graduate students starting upon a career in the lastics industry. We have nothing quite like it in Great Britain. Ninety-seven experiments are described and twenty-seven test methods. A distinctive character of the book is the way in which these exercises are put together ; they all need thought rather than mere routine attention. Among the tests are such interesting topics as the determination of $p \mathrm{H}$, acid number, and degree of unsaturation (akin to the iodine number). In the arts and crafts there should be a future for this compilation, since the use of methacrylate esters and the various polyvinyls is increasing in these fields. It would be advantageous if museum and gallery workshops could be provided with this book, for their skilled technicians to see what can be done with polymers and condensation products in general.

The attractive format and neat arrangement of the text are commendable.

F. IAN G. RAWLINS

The Gas-filled Triode

By G. Windred. OPp. 72. (London: Hulton Press, Ltd., 1946.) 3in $6 d$. net.

7 HIS moghothes outlines both the historical and pactical aspects of the gas-filled triode; these defices find many applications in industrial control (12nd trigger circuits. The author gives a complete list of those models available at the present time, together with their operating conditions and possible circuits.

Systematic Inorganic Chemistry of the Fifth-andSixth-Group Non-ppetallic Elements

By Prof. Don Mrost and Horace Russell, Jr. (Prentice-Halh fhendistry Series.) Pp. $\mathrm{xx}+423$. (London: offord University Press, 1946.) 21s. net. 7 HIS $40 \mathrm{k}$ was published in the United States in 1944 , and was reviewed in Nature (154, 723; 1946. The present issue has a new title-page, but is otherwise the same. The book is one which can be recommended to students, and the fact that it has been made available in Britain is to be welcomed. 